\title{
Risk factors for advanced liver fibrosis in HIV-infected individuals: role of the metabolic syndrome
}

\author{
F Blanco*, P Barreiro, P Ryan, E Vispo, L Martin-Carbonero, P Tuma, \\ P Labarga, J González-Lahoz and V Soriano
}

Address: Hospital Carlos III, Madrid, Spain

* Corresponding author

\author{
from Ninth International Congress on Drug Therapy in HIV Infection \\ Glasgow, UK. 9-13 November 2008 \\ Published: 10 November 2008 \\ Journal of the International AIDS Society 2008, I I (SuppI I):PI37 doi:I0.II86/I758-2652-II-SI-PI37
}

This abstract is available from: http://www.jiasociety.org/content/I I/SI/PI37

(c) 2008 Blanco et al; licensee BioMed Central Ltd.

\section{Background}

Liver damage in HIV patients may result from multiple factors. The availability of reliable non-invasive tools to measure liver fibrosis, such as transient elastometry (FibroScan), has permitted the screening of large populations.

\section{Methods}

Cross-sectional study of all HIV outpatients who underwent examination by FibroScan at one HIV reference clinic since 2005. Advanced liver fibrosis (ALF) was defined as hepatic stiffness $>9.5$ kiloPascals, which corresponds to Metavir stages F3-F4 in the liver biopsy. Main demographics, alcohol abuse, antiretroviral exposure, biochemistry, HOMA index, immune and viral parameters, and hepatitis B or C status were evaluated.

\section{Summary of results}

A total of 681 consecutive HIV patients $(64 \%$ injecting drug users; mean age 43 years; $78 \%$ male; $77 \%$ on antiretroviral therapy) had a valid FibroScan evaluation. Main characteristics: mean CD4 count 524 (309) cells/mm3, plasma HIV-RNA $<50 \mathrm{cp} / \mathrm{mL} 72 \%$, HBsAg+ $8.5 \%$, HCVRNA+ 60\%, mean BMI $23.6(3.9) \mathrm{kg} / \mathrm{m} 2$, past and current alcohol abuse (>60 g/d) 33\% and 10\%, respectively. ALF was diagnosed in 215 (32\%).

In the univariate analysis, significant differences were found between patients with and without ALF for mean age (44 vs. 42 years), risk behaviour (IDU 81 vs. 54\%,
MSM 11 vs. $33 \%$, heterosex 6 vs. $12 \%$ ), past alcohol abuse (50 vs. $26 \%$ ), mean CD4+ count ( 469 vs. 550 cells/mm3), HCV-RNA+ (77 vs 52\%), ALT >50 IU/L (29 vs 9\%), mean plasma glucose (127 vs. $116 \mathrm{mg} / \mathrm{dL}$ ), triglycerides (223 vs. $172 \mathrm{mg} / \mathrm{dL}$ ), and total cholesterol (177 vs. $188 \mathrm{mg} / \mathrm{dL}$ ), HOMA index (4.5 vs. 3.2 ), past exposure to $\mathrm{ddI}+/-\mathrm{d} 4 \mathrm{~T}$ ( 51 vs. $40 \%$ ), and mean months on NVP (11 vs. 16$)$, LPV (13 vs. 8 ), atazanavir ( 7 vs. 5 ), tenofovir ( 21 vs. 18 ) as well as any antiretroviral ( 85 vs. 78 ).

In a multivariate model (OR, 95\% CI), older age (1.08, 1.04-1.13), past alcohol abuse (2.62, 1.60-4.28), exposure to ddI and/or d4T (1.94, 1.20-3.16), higher HOMA index $(1.25,1.04-1.51)$ and elevated ALT $(1.05,1.03-$ 1.06) were all independently associated with ALF; in contrast, chronic hepatitis $\mathrm{B}$ or $\mathrm{C}$ were no longer associated with ALF.

\section{Conclusion}

Former alcohol abuse and non-alcoholic steatohepatitis as a result of insulin resistance and/or exposure to dideoxy-nucleosides represent an emerging cause of ALF in HIV patients.

\section{References}

I. Vergara S, et al:: The use of transient elastometry for assessing liver fibrosis in patients with HIV and hepatitis $C$ virus coinfection. Clin Infect Dis 2007, 45:969-974.

2. Soriano $V$, et al: Antiretroviral drugs and liver injury. AIDS 2008, 22: $1-13$. 